\title{
Study on the Application of Horticultural Therapy in the Landscape Design of the Community for the Aged
}

\author{
Guo Yunjia
}

School of architecture and art, Hebei College of architectural engineering, Qiaodong District, Zhangjiakou, Hebei, China 382672351@qq.com

\begin{abstract}
From the initial "forest bath" and "aromatherapy" to "forest therapy" and "horticultural therapy", after medical verification, this kind of behavior is beneficial to the body. In a series of changes of social role and economic status, the elderly need to find a way to adjust their living conditions and relieve their psychological pressure. The community is one of the most convenient and frequently used outdoor places for the elderly. The highfrequency utilization undoubtedly makes the community the best place to use horticultural therapy, and at the same time, it can give full play to the effect of horticultural therapy. In this paper, horticultural therapy is applied to the landscape design of the elderly community. Firstly, the relevant theories of horticultural therapy are discussed. Secondly, the physiological characteristics, psychological characteristics and behavioral characteristics of the elderly are analyzed. Thirdly, the current situation of landscape design in zixinyuan community is analyzed. Finally, the application suggestions in landscape design are put forward.
\end{abstract}

Keywords: Horticultural Therapy, Retirement community, Landscape design, application research

\section{园艺疗法在养老社区景观设计应用研究}

\section{郭旳嘉}

河北建筑工程学院建筑与艺术学院, 桥东区, 张家口, 河北, 中国 382672351@qq.com

\section{摘要}

从最初的 “森林浴”、“芳香疗法” 发展成为 “森林疗法” 与 “园艺疗法”, 经过医学验证, 此类行为 活动对身体有益。在社会角色、经济地位的一系列变化中, 老年人需要寻求一种手段来调整生活状态, 减缓心理压力，而小区是老年人最方便、最经常使用的户外场所之一，高频率的利用无疑使得社区成 为园艺疗法最佳的使用场所，同时也能最大发挥出园艺疗法的功效。本文是将园艺疗法应用于养老社 区的景观设计之中，首先对园艺疗法相关理论进行论述，其次从老年人的生理特征、心理特征与行为 特征进行分析，再次分析了紫金苑小区景观设计现状，最后提出景观设计中应用建议。

关键词: 园艺疗法, 养老社区, 景观设计, 应用研究

\section{1. 研究背景}

\section{1. 人口老龄化}

目前, 人口老龄化是世界性趋势, 在国际上较为通 用的划定标准是达到 60 岁及以上人口占国家总人口占 比的 $10 \%$, 又或者是超过 65 岁及以上人口达到国家总人 口占比的 7\%, 在 1999 年我国达到此标准, 这也标志着 我国进入 “老年型” 国家行列。从图一来看, 我国 65 岁 


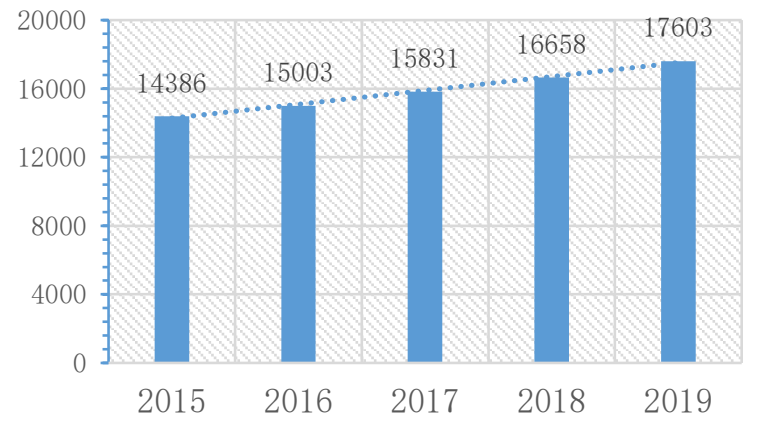

图 1 2015-2019 年中国 65 岁及以上人口（单位: 万 人)

在老龄化的社会现实下, 无论是政府机构、商主题 的经营性行为, 都对老年人更加关注。在养老社区如雨 后春笋般涌现，且资质参差不齐的大环境下，探索如何 营造良好的养老社区景观设计成为重要的研究方向。

\section{2. 园艺疗法的兴起}

园艺疗法最早出现于古希腊及古罗马。在当时人们 认为通过与大自然的接触, 如在室外活动、接触植物等 方法, 可以影响人的身心健康。在 18 世纪末, 对园艺 疗法的探索及应用逐渐增多。后来于 1948 年 Ms. Ruth Presley 正式提出园艺疗法这一专有名词, 即英文 Horticultural Therapy, 开始成为一门独立的学科。园艺 疗法也迅速的由欧美国家发展至日本、韩国等发达国家。

现如今, 人类疾病问题愈加复杂, 一般的医学治疗 手段以及无法满足现在的大环境。园艺疗法作为一种医 学辅助手段, 也被广泛地应用于医疗机构、住宅等环境 的建设中。园艺疗法方兴未艾。园艺疗法也可以简单解 释为利用园艺进行 “治疗” , 通过植物以及相关活动达 到康养的目的。为建设符合中国国情的老年宜居环境, 园艺疗法也常用来解决养老社区中老年人活动过程中 的不适用性。

\section{2. 园艺疗法相关概念}

\section{1. 定义}

园艺疗法作为新兴的医疗辅助手段, 以其中 “疗法” 二字来看, 是以对人进行治疗。而园艺疗法是通过 “绿” 的自然环境来达到缓解压力、促进内分泌系统循环、增 强自身免疫系统的目的, ${ }^{[1]}$ 是一种医疗手段与园艺手法 相结合的实践技术, 也是一种园艺欣赏与心理相结合的 文化, 通常也被称为预防医学植物疗法。园艺疗法也可 分为狭义、广义两种, 前者主要是让人参与植物的成长 过程, 感受植物的生长变化, 借此调节与整理自身情绪; 而广义则是指所有人群参与植物栽培、园艺操作、维护 管理等一系列园艺活动过程中, 从而达到舒缓心情、放
松情绪，从中获得满足感、存在感，提高参与者身体机 能的目的 (图 2)。实施园艺疗法的场所主要为植物园、 福利院、养老院、精神疗养院、住宅等。

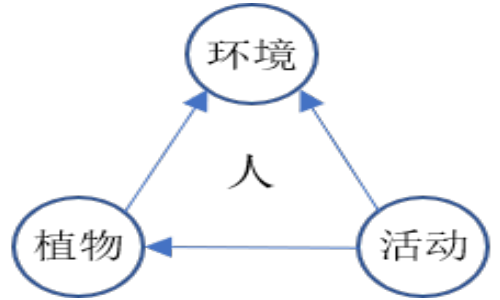

图 2 园艺疗法景观结构

\section{2. 适用人群}

园艺疗法治疗对象逐渐趋于多元化，根据不同人群 的心理、生理需求，笔者将适用人群大体分为三类: 第 一类为儿童、青少年、成人等健康人士，儿童、青少年 处于成长的发育期, 表现为活泼、好动、运动量大等生 理特征, 心理特征则为产生叛逆心理, 自主性独立性增 强, 成年人器官发育完全且承担社会责任; 第二类主要 是亚健康类人群, 即处于健康与疾病之际的一个状态, 包括身体亚健康、心理亚健康, 高发人群主要为 $40-50$ 岁左右; 第三类主要的治疗对象为残疾人、老年人、社 会弱者、心理障碍患者、精神患者、智能障碍者等人群。 老年人的心理健康问题主要体现在孤独感、恐惧感、失 落感、抑郁症、以及老年痴呆等方面。残疾人、智能患 者等人群由于部分生理缺陷, 在日常生活中遭遇更多的 挫折和困难, 在心理上主要表现为性格孤僻、强烈的自 卑感。园艺疗法可以增加各类人群之间交流的机会, 提 高活动空间, 解决负面心理问题以及释放压力, 提高幸 福感和获得感等。

\section{3. 园艺疗法作用机制}

园艺疗法主要是通过静态与动态这两种疗法来实 现的。静态疗法是通过人的视觉、听觉、嗅觉、味觉、 触觉等方面的感受下进而获得的。而另一种动态机制则 是在人与植物建立关系下, 并在此过程中所达到的效果。

静态疗法。静态疗法主要是通过植物、五感功能、 水景设计等方法进而实现。植物可以吸 $\mathrm{CO}_{2}$ (二氧化碳) 、 释放 $\mathrm{O}_{2}$ (氧气), 并且可以增加湿度、降低温度以及防尘 等功能, 与植物接触的过程中, 感受大自然, 从而得到 情绪上的释放, 减少焦虑以及紧张。五感治疗主要有色 彩治疗、听觉疗法、芳香治疗、味觉疗法、触觉疗法。 比如色彩疗法, 各类植物具有不同的色彩、形状等特征, 带来丰富的视觉观赏效果（表 1)。 
表 1 色彩对人生理、心理的影响表

\begin{tabular}{|c|c|c|}
\hline \multirow{2}{*}{ 颜色 } & \multicolumn{2}{|r|}{ 色彩代表的意义及影响 } \\
\hline & 代表意义 & 对人的影响 \\
\hline 红色 & $\begin{array}{l}\text { 热情、奔 } \\
\text { 放、喜悦、 } \\
\text { 活力 }\end{array}$ & $\begin{array}{l}\text { 刺激神经系统、增加肾上腺素分 } \\
\text { 泌、增加血液循环、情绪奔放、 } \\
\text { 产生热烈、活泼的情绪。 }\end{array}$ \\
\hline 橙色 & $\begin{array}{l}\text { 温暖、古 } \\
\text { 老、欢欣、 } \\
\text { 知识 }\end{array}$ & 诱发食欲、帮助恢复健康和吸收 \\
\hline 绿色 & $\begin{array}{l}\text { 青春、希 } \\
\text { 望、和平、 } \\
\text { 生长 }\end{array}$ & $\begin{array}{l}\text { 镇静神经、降低眼压、解除眼疲 } \\
\text { 劳、改善肌肉运动能力、缓解消 } \\
\text { 极情绪。 }\end{array}$ \\
\hline 黄色 & $\begin{array}{l}\text { 光明、辉 } \\
\text { 煌、灿烂、 } \\
\text { 智慧 }\end{array}$ & $\begin{array}{l}\text { 促进血液循环、增加唾液腺的分 } \\
\text { 泌、引起食欲、促进情绪稳定。 }\end{array}$ \\
\hline 蓝色 & $\begin{array}{l}\text { 平缓、安 } \\
\text { 静、寞、 } \\
\text { 空旷 }\end{array}$ & $\begin{array}{l}\text { 调节神经、镇静安神、缓解紧张 } \\
\text { 情、绐疗失眠、降低血压。 }\end{array}$ \\
\hline 白色 & $\begin{array}{l}\text { 纯洁、纯 } \\
\text { 粹、神圣 }\end{array}$ & $\begin{array}{l}\text { 加快新陈代谢、减轻疼痛、消除 } \\
\text { 急躁情绪、保持血压正常。 }\end{array}$ \\
\hline 紫色 & $\begin{array}{l}\text { 权威、高 } \\
\text { 贵、庄重、 } \\
\text { 优雅 }\end{array}$ & 减轻心脏疼痛、缓解头痛、缓解 \\
\hline
\end{tabular}

动态疗法。动态疗法是参与者通过栽培、玩要、记 忆等进行治疗。栽培治疗顾名思义是指参与者耕耘植物、 农作物，参与翻土、碎土、平整、播种、插积、浇水、 除草等多种栽培作业, 从而增进新陈代谢、提升身体自 我感觉、保持以及扩大培育过程中的乐趣及喜悦, 亲自 体验培育活动, 满足基本作业愿望, 进行自我尊重、自 我评价、自我实现。 ${ }^{[2]}$ 度过。玩要治疗主要对象为儿童、 青少年等, 正在大自然环境中玩要、打闹, 增进玩伴之 间以及孩子与家长之间的感情。在 1973 年-1975 年, 瑞 典斯德哥尔摩市的一所儿童门诊曾进行过玩要治疗的 实验, 结果显示其疗法对儿童的生理、心理方面产生良 好的影响 ${ }^{[3]}$ 。

\section{3. 老年人特征分析}

\section{1. 老年人生理特征分析}

当进入老年阶段后, 身体机能的各个方面也会发生 退化。这主要体现在五感变化、运动系统以及神经系统 的变化。随着年龄的的增大, 人体的视力明显衰退, 主 要是在视觉距离、视觉敏感度、色彩辨识等方面的能力 明显下降; 听觉能力衰退, 在声音感受、分辨方面能力 减弱; 对周围环境感知力下降, 在所处环境中温度、湿 度等方面不能及时作出反应; 嗅觉能力退化, 对外界气 味敏感度降低; 味觉机体功能也有衰退的趋势; 人体会 出现骨质疏松、韧带纤维化等状况, 肌肉力量以及控制 力发生明显退化, 运动能力减退; 老年人中枢神经系统
退化，容易出现反应迟钝、记忆力减退等现象。

\section{2. 老年人心理特征分析}

老年人随着生理机能的逐渐衰退, 心理上也出现了 衰老特征, 体现为以下几个方面: a. 焦虑和抑郁, 具体 症状表现为压抑、悲观、厌食等, 使得老年人急躁、固 执，长久负面情绪的堆积也会导致老年人身体疾病的发 生。b. 孤独和依赖, 感官机能的衰退使得老年人与外界 交流也存在着一定的障碍。c. 缺乏成就感, 在社会角色、 经济地位的变化里, 由家庭供给者转变为被赡养者, 老 年人需要重新寻找定位, 在此过程中心理产生一系列负 面情绪, 怀疑自身价值, 自信心不足, 从而丧失生活的 动力。

\section{3. 老年人行为特征分析}

老年人日常活动场所主要为所居住的社区，在社区 中的场地和花园中进行娱乐、休闲等活动 ${ }^{[4]}$ 。根据老年 人的日常活动习惯、生活活动范围等多方面, 对老年人 行为特征进行分析, 且总结为以下三方面: $a$. 群体聚集 性。因相同的兴趣爱好, 一部分老年人共同发起活动、 组织社团, 这表现为同一性。由于不同的生活经历、喜 好特长以及健康状况, 造就了每个老年人爱好的差异性, 从而形成各型各色的团体活动。 $\mathrm{b}$. 时节地域性。老年人 所在地区的地理区域、气候变化、环境污染程度都将直 接影响老年人的行为规律, 由于冬季气候寒冷、空气污 染严重, 大多数老人选择待在室内, 但在其他三个季节 中, 室外活动时间远高于冬季。c. 区域选择性。其行为 特征是指老年人喜欢在自己熟悉的场所进行的习惯性 活动 ${ }^{[5]}$ 。

\section{4. 紫金苑小区景观设计应用研究}

\section{1. 小区景观设计现状分析}

随着老龄化日益加剧, 建造了许多以老年人为主要 受众群体的社区, 这类社区在声环境、光环境、无障碍 设施等方面, 给予了足够的关注与重视。而景观设计方 面大多数是作为建筑的附属品而存在, 对老年人的生理 特征、心理特征、行为特征、以及需求等方面并没有足 够的重视。紫金苑小区位于河北省石家庄市谈固东街和 跃进路交口, 该小区空间组织较不合理, 景观利用率较 低, 缺少细致的设计思考, 空间尺度过大, 造成疏离感; 景观气候性考虑不全面, 由于地势高差, 且对于气候因 素的思考不够充分, 增加危险发生的可能性; 缺乏河北 本地民族文化特征, 地域性不足。 


\section{2. 小区景观设计应用建议}

铺装设计。在小区中, 应尽量避免使用纹理过于复 杂的硬质铺装, 采用表面纹理明显、质感清晰地材质; 在满足车行、步行、消防通道等基础需要以及休闲、娱 乐等功能的前提下, 尽可能地减少硬质铺装, 多设置为 塑胶铺装, 降低老年人在活动过程中意外受伤的可能性; 在步行道路的设计上, 避免过大过陡的坡度, 进行合理 地规划。

植物配置。在小区内, 增加植物的种植量, 从而营 造的丰富的植物景观, 在美化社区环境的同时, 增加空 气湿度、提高空气中负氧离子的浓度, 将室外环境建造 成 “天然氧吧”, 增加老年人外出活动次数, 加强身体 素质; 在植物的选择上, 种植对人体有益的药用植物, 不仅可以释放对人体有利气体, 吸附尘埃、杀菌, 还可 以提供制药的原料, 如桔梗、益母草、曼陀罗等植物; 将带有气味的植物种植在方便老年人接近的场地, 如桂 花、玉兰、月季、薄荷等芳香型植物, 运用芳香植物刺 激老年人嗅觉感官, 改善身体状况、调节情绪。

景观小品。小区内园艺疗法场地分为展示区与活动 体验区两部分。在展示区场地中, 以老年人即小品使用 者参与其中, 设置园艺花篮、种植床等小品, 增加老年 人满足感, 加强对生活的信心。在活动体验区中, 设置 实习花坛、操作间、温室大棚等场所, 让老人在其中学 习园艺疗法的方法与技巧, 使参与者接触多种多样的植 物, 从而达到锻炼身体、舒缓心情的目的。实习花坛区 域可设置多种不同高度，以应对身体状况不同的老年人， 进行种植、除草、浇水、剪纸、采摘果实等园艺活动, 并且将采摘的瓜果、蔬菜、花卉等植物赠送给亲朋好友, 进行自我价值的实现。

\section{项目基金}

本文为河北建筑工程学院硕士研究生创 新基金项目 XY202022《寒冷地区住宅建筑阴 影区冬季景观营造研究——以石家庄市为例》 的阶段性成果之一。

\section{References}

[1] Zhang Jw,Liu W. (2009)Horticultural therapy. chinese landscape architecture, 7:19-23.

[2] Li Sh. (2011) Introduction to horticultural therapy. China Forestry Press,Beijing.

[3] Lindquis T. (1977) Therapy through play. Arlin GtonBooks,London.

[4] Lei Yh, Jin Hx, Wang Jy. (2011) Current situation and Prospect of rehabilitation garden research. chinese landscape architecture, 4:31-36.
[5] Li S. (2000) Establishing the subject system of horticultural therapy with Chinese characteristics as early as possible (I). chinese landscape architecture, 3: 17-19.

[6] Wei Ss. (2004) A brief analysis of humanized design of activity space for the elderly in forest. Fujian Forestry Science and technology, 31: 79-83.

[7] Lu Cl. (2013) Horticultural therapy and its application in gardens. China Academy of Forestry Sciences, Beijing.

[8] An L. (2013) Study on residential area planning and design based on the daily travel characteristics of the elderly. Dalian University of Technology, Dalian. 